\title{
Aprendizagem histórica e formação de professores dos anos iniciais na Universidade do Minho (Portugal): a articulação entre a prática e a investigação em educação histórica'
}

\author{
Historical learning and training teacher from early years at University \\ of Minho (Portugal): the articulation between practice and research \\ in history education
}

\section{Aprendizaje histórico y formación de profesores para los primeros años de escolaridad en la Universidad de Minho (Portugal): la articulación entre la práctica y la investigación en la educación histórica}

\section{Glória Solé}

Departamento de Estudos Integrados de Literacia, Didáctica e Supervisão, Universidade do Minho, Professora auxiliar https://orcid.org/0000-0003-3383-5605

Resumo: Este texto tem como objetivo apresentar a investigação em Educação Histórica desenvolvida no Instituto de Educação da Universidade do Minho (Portugal) no âmbito dos vários mestrados profissionalizantes de formação de professores, em especial dos professores dos anos iniciais (seis aos 12 anos). Apresenta-se uma breve contextualização do modelo de formação de professores desenvolvido na nossa instituição, principalmente desde 2008, com a implementação do modelo de Bolonha. Destaca-se a relevância atribuída à articulação entre prática pedagógica e investigação, as implicações da investigação no contexto educativo, bem como no desenvolvimento profissional dos futuros professores, alicerçada no paradigma construtivista, operacionalizado no modelo de aula-oficina, que fomenta o papel do professor-investigador social e os alunos como agentes da construção do conhecimento histórico. Exemplica-se esse modelo a partir de alguns estudos empíricos implementados pelos nossos formandos com crianças e jovens, que se focam em conceitos de segunda ordem (mudança, narrativa, evidência e significância) relacionados com o pensamento histórico e a consciência histórica, e outros estudos que integram ainda a educação

Este trabalho é financiado pelo Centro de Investigação em Educação (CIEd), projetos UID/CED/1661/2013 e UID/CED/1661/2016, Instituto de Educação, Universidade do Minho, através de fundos nacionais da FCT/MCTES-PT.

2 Doutora em Estudos da Criança pela Universidade do Minho; Mestre em História das Instituições e Cultura Moderna e Contemporânea pela Universidade do Minho (Portugal). 
patrimonial, na linha de investigação em cognição histórica, que se tem desenvolvido na Universidade do Minho (Portugal).

Palavras-chave: Educação histórica. Cognição histórica. Formação de professores dos anos iniciais.

Abstract: This text aims to present the research in History Education developed at the Institute of Education of the University of Minho (Portugal) under the various professional master's degrees of teacher training, especially of teachers from the early years (6 to 12 years). A brief contextualization of the teacher education model developed at our institution is presented, especially since 2008, with the implementation of the Bologna model. The relevance attributed to the articulation between pedagogical practice and research, the implications of research in the educational context, as well as in the professional development of future teachers, based on the constructivist paradigm, operationalized in the workshop class model, which fosters the role of the teacher as social research and students as agents of the construction of historical knowledge. This model is exemplified by some empirical studies implemented by our trainee's teachers with children and young people, which focus on second order concepts (change, narrative, evidence and significance) related to historical thinking and historical consciousness, and other studies that also integrate heritage education, in line with historical cognition research, which has been developed at the University of Minho (Portugal).

Keywords: History education. Historical cognition. Teacher training from the early years.

Resumen: Este texto tiene como objetivo presentar la investigación en Educación Histórica desarrollada en el Instituto de Educación de la Universidad de Minho (Portugal) bajo los diversos másteres profesionales de formación docente, especialmente de maestros de los primeros años (6 a 12 años). Se presenta una breve contextualización del modelo de formación docente desarrollado en nuestra institución, especialmente desde 2008, con la implementación del modelo de Bolonia. Se destaca la relevancia atribuida a la articulación entre la práctica pedagógica y la investigación, las implicaciones de la investigación en el contexto educativo, así como en el desarrollo profesional de los futuros maestros, basado en el paradigma constructivista, operacionalizado en el modelo de clase de taller, que fomenta el papel del maestro- investigador social y estudiantes como agentes de la construcción del conocimiento histórico. Este modelo se ejemplifica en algunos estudios empíricos implementados por nuestros profesores en formación con niños y jóvenes, que se centran en conceptos de segundo orden (cambio, narrativa, evidencia y relevancia) relacionados con el pensamiento histórico y la conciencia histórica, otros estudios también integran la educación patrimonial, en la línea de investigación en cognición histórica, desarrollada en la Universidad de Minho (Portugal).

Palabras clave: Educación histórica. Cognición histórica. Formación docente de los primeros años.

Recebido em 27 de agosto de 2019 Aceito em 6 de fevereiro 2020

Publicado em 15 de junho de 2020 


\section{INTRODUÇÃO}

Este texto ${ }^{3}$ inicia com uma breve contextualização do que temos vindo a desenvolver no ensino de História e no âmbito da Educação Histórica na nossa instituição, começando por apresentar e reflectir sobre o modelo de formação de educadores e professores em Educação Básica com relação ao ensino da História e sua didática, bem como à relevância atribuída à articulação entre prática pedagógica e investigação. Dá-se particular ênfase ao estágio profissional que, na nossa instituição, apresenta um modelo que reforça a componente investigativa alicersada na prática pedagógica. 0 modelo de estágio proposto pela Universidade do Minho

pretende conferir à prática pedagógica uma natureza transformadora [...] e emancipatória, onde os futuros educadores e professores devem educar investigando e investigar educando, e onde a ação educativa envolve a confluência de saberes disciplinares e educacionais, experienciais e teóricos, substantivos e processuais. (VIEIRA et al., 2013, p. 2644).

Com o objetivo de compreender o papel da investigação no estágio, foi analisado um corpus de 14 relatórios de estágio ${ }^{4}$ de dois mestrados nos quais temos tido um papel preponderante na orientação na área da História, nomeadamente o Mestrado em Educação Pré-escolar e Ensino do $1^{\circ}$ Ciclo do Ensino Básico e o Mestrado em Ensino do $1{ }^{\circ}$ CEB e do $2 .^{\circ}$ CEB. Assim, na terceira parte apresentam-se vários estudos empíricos implementados com crianças e jovens sobre conceitos de segunda ordem/conceitos metahistóricos (mudança, narrativa, evidência e significância) e outros estudos que articulam a Educação Histórica e a Educação Patrimonial, estudos estes integrados na linha de investigação em cognição histórica, implementados em contexto de estágio, que resultaram em relatórios finais de mestrado com forte pendor investigativo. Estas investigações, apesar de desenvolvidas no âmbito da prática profissional de estágio, pela qualidade investigativa que apresentam, sustentadas em referências que integram pressupostos teóricos e epistemológicos da Educação Histórica e questões metodológicas da pesquisa empírica desenvolvida sobre as ideias de crianças, têm vindo a revelar estudos importantes no âmbito da investigação nesta área. Por isso, a par de toda a investigação que o grupo de pesquisa da Universidade do Minho tem desenvolvido

Este texto está escrito em Português de Portugal.

40 relatório de estágio corresponde a um projeto de intervenção pedagógica desenvolvido no âmbito do estágio e que integra uma componente investigativa. É defendido em provas públicas, com um júri constituído por três docentes, o Diretor do Mestrado, o Arguente principal, que geralmente é um docente convidado da área da especialização, e o orientador supervisor do aluno estagiário. 
nesta área, será pertinente dar a conhecer também estes trabalhos investigativos realizados no âmbito do estágio profissional.

Assim, este texto está divido em três secções: 1) Formação de Professores na Universidade do Minho e o ensino de História; 2) 0 Estágio Profissional na Universidade do Minho; 3) A relação entre a teoria e a prática na formação dos professores: projetos investigativos em contexto de estágio.

\section{FORMAÇÃO DE PROFESSORES NA UNIUERSIDADE DO MINHO E O ENSINO DE HISTÓRIA}

A reorganização dos cursos universitários na União Europeia foi desencadeada após o Tratado de Bolonha (2001), tendo adotado ritmos de implementação diferentes nos vários países (Portugal, 2006a). Adotou-se um sistema de formação organizado em três ciclos de estudo: $1^{\circ}$ Ciclo com a duração mínima de três anos- Licenciatura; $2^{\circ}$ Ciclo com a duração de um ano e meio a dois anos - Mestrado; $3^{\circ}$ Ciclo - doutoramento com duração variável. Apesar desta unanimidade, a implementação gerou planos curriculares com algumas especificidades nos países subscritores e variações nos planos curriculares da Licenciatura em Educação Básica e nos Mestrados de Formação de Educadores e Professores do 1. e do 2. CEB, mesmo em nível Nacional (MEL0, 2015).

Restringir-nos-emos aos dados relativos à Universidade do Minho (UM) e à formação oferecida entre 2009 e 2018. Passaremos a explicar o contexto de formação ministrado na Universidade do Minho no âmbito da Licenciatura em Educação Básica e nos vários mestrados de formação de professores e educadores (Mestrado em Educação Préescolar, Mestrado em Educação Pré-escolar e Ensino do 1. ${ }^{\circ}$ CEB, Mestrado do ensino do 1. ${ }^{\circ}$ CEB e do $2^{\circ}$ CEB (2009-2015) reformulado e divido a partir de 2015 em dois mestrados, nomeadamente Mestrado em Ensino do $1 .^{\circ}$ CEB e de Matemática e Ciências da Natureza do $2^{\circ}$ CEB e Mestrado em Ensino do 1. ${ }^{\circ}$ CEB e de Português e História e Geografia de Portugal do 2. CEB) e o nosso papel na formação de Educadores e Professores, nesta área da formação de futuros professores em relação ao ensino de História, assunto sobre o qual já várias vezes nos debruçamos (LLONCH; SOLÉ, 2014; SOLÉ; VARELA, 2013; SOLÉ, 2016). ${ }^{5}$

5 Breve explicação do sistema educativo português para se compreender a formação de professores em Portugal. 0 sistema educativo português é constituido por três ciclos de Ensino Básico: $11^{\circ}$ Ciclo do Ensino Básico (1..$\left.^{\circ} \mathrm{CEB}\right)$, que corresponde aos primeiros quatro anos de escolaridade; $2 .^{\circ}$ Ciclo do Ensino Básico (2..$^{\circ} \mathrm{CEB}$ ), que corresponde ao $5 .^{\circ}$ e $6 .^{\circ}$ anos; $\circ 3 .^{\circ}$ Ciclo do Ensino Básico (3. $\mathrm{CEB}$ ), que corresponde ao $7 .^{\circ}, 8^{\circ}$ e $9 .^{\circ}$ anos, e o Ensino Secundário, que corresponde ao $100^{\circ}$, $11 .^{\circ}$ e $12 .^{\circ}$ anos. A escolaridade obrigatória em Portugal é de 12 anos de escolaridade. 
Na Licenciatura Básica, ministrada na Universidade do Minho, o primeiro contacto com a Didática do ensino da história começa só no $3 .^{\circ}$ ano, numa disciplina que leciono e que se designa de Iniciação à Didática de Estudo do Meio (2. ${ }^{\circ}$ semestre, 5 ECTS), que integra as didáticas específicas de duas áreas, Estudo do Meio Natural e Estudo do Meio Social, designação que se baseia no Programa do $1^{\circ}{ }^{\circ}$ ciclo, na nomenclatura da disciplina de Estudo do Meio, que incorpora a área disciplinar de História.

0 conhecimento epistemológico da História indispensável para a Didática e Educação é adquirido, em parte, na disciplina de História de Portugal (1. ${ }^{\circ}$ semestre do $3 .^{\circ}$ ano), a par de questões sobre a importância da História e do conhecimento histórico científico, bem como o papel das fontes, na sua diversidade e estatuto, e como estas podem ser questionadas e usadas como evidência histórica (COLLINGWOOD, 2001), assumindo também relevância a teoria do ensino da História, com abordagens em que se procura dar ainda uma visão sobre a História da História em Portugal (SOLÉ, 2014b; SOLÉ, 2016).

Com o processo de Bolonha e a reformulação dos cursos, na Licenciatura em Educação Básica, é dada maior enfase à componente científica das áreas disciplinares e um menor peso à pedagogia e à prática, ou seja, às Didáticas, mas como docente de várias áreas cient́ficas relacionadas com o ensino de História, nomeadamente História de Portugal e o módulo de Património Cultural, procuro aqui promover uma abordagem de ensino isomórfica com os alunos/formandos, introduzindo pressupostos didáticos específicos nas estratégias que implemento em sala de aula e na orientação dos trabalhos. No papel de professora-investigadora que realizo com os meus alunos/formandos, procuro promover mudanças nas suas práticas de docência, desenvolver competências de interpretação e questionamento das fontes, ao nível do uso da evidência.

0 processo de formação nesta área de Didática de Estudo do Meio, iniciado na Licenciatura em Educação Básica da Universidade do Minho, tem-se caracterizado pela articulação dos seus saberes específicos (ensino das Ciências, da História e Geografia a crianças) numa abordagem que tende a articular a teoria à prática, integrando a mais recente investigação nesta área em nível nacional e internacional, relacionado com estudos empíricos em educação histórica e patrimonial (SOLÉ, 2016).

No âmbito dos vários mestrados de formação de professores, reformulados à luz das orientações de Bolonha (PORTUGAL, 2006b), surgem várias unidades curriculares (UCs) que ampliam a formação no campo da didática da História e da Geografia, incorporam contributos epistemológicos da Educação Histórica, revelador do estatuto de autonomia alcançado da área, como a UC de Didática de História e Geografia para a Educação Básica (2. semestre do $1^{\circ}$ ano), comum aos três mestrados de Educação Básica, e Linguagem e pensamento histórico

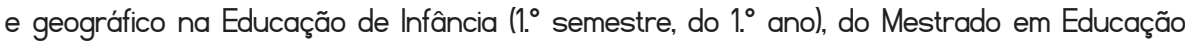
Pré-escolar, todas UCs de cinco ECTS. A Unidade Didática de História e Geografia para a Educação Básica tem como principais objetivos: 
a) mobilizar conceitos e perspetivas atuais no âmbito do ensino e aprendizagem de História e Geografia relativos à Educação Histórica e Geográfica;

b) analisar conteúdos programáticos tendo em conta a articulação entre as competências do ensino de História e Geografia na Educação Básica e a gestão dos programas oficiais;

c) conceber e implementar processos de ensino e aprendizagem na lógica da metodologia investigativa no ensino de História e Geografia;

d) planear experiências de aprendizagem de acordo com os contextos concretos de ensino de História e Geografia que incluam metodologias e estratégias diversificadas e potenciadoras de uma Educação Histórica e Geográfica e de uma cidadania ativa;

e) analisar, avaliar e produzir materiais pedagógicos utilizando recursos diversificados, incluindo os media;

f) refletir sobre práticas em Educação Histórica e Geográfica no âmbito das preocupações de uma Educação para a Cidadania.

\section{O ESTÁGIO PROFISSIONAL NA UNIUERSIDADE DO MINHO}

Com o Processo de Bolonha ${ }^{6}$ em Portugal, foram extintas as licenciaturas em ensino de quatro ou cinco anos que conferiam habilitação para a docência e foram criados os mestrados em ensino, com a duração de um a dois anos (60 a १२० ECTS), em curso desde 2008/2009. 0 novo sistema de atribuição de habilitação para a docência, definido no DecretoLei n. 43/2007, valoriza a "fundamentação da prática de ensino na investigação" e sublinha

a necessidade que 0 desempenho dos educadores e professores seja cada vez menos o de um mero funcionário ou técnico e cada vez mais 
o de um profissional capaz de se adaptar às características e desafios das situações singulares em função das especificidades dos alunos e dos contextos escolares e sociais. (PORTUGAL, 2007).

Sustenta-se que a iniciação à prática profissional promova "uma postura crítica e reflexiva em relação aos desafios, processos e desempenhos do quotidiano profissional." (VIEIRA et al., 2013, p. 2641-2642).

A UC Estágio Profissional trata-se de uma UC obrigatória, de natureza anual, situada no $2^{\circ}$ ano, e tem entre os seus objetivos aprofundar as competências disciplinares, por referência aos currículos nacionais e em articulação com os interesses e necessidades de formação do $10^{\circ}$ CEB e nas várias áreas de Docência (Matemática, Ciências da Natureza, Português e História e Geografia de Portugall) do $2 .^{\circ} \mathrm{CEB}$, promover a intervenção crítica nos contextos pedagógicos no quadro de uma visão transformadora da pedagogia escolar e incentivar uma cultura investigativa e colaborativa na formação profissional. ${ }^{7}$ Daí que nela seja dado papel medular ao desenvolvimento de um Projeto de Intervenção Pedagógica Supervisionada (PIPS) que exige certo domínio de procedimentos afetos à construção e à implementação de instrumentos de recolha de dados sobre os contextos de intervenção e as práticas pedagógicas desenvolvidas, e à análise e reflexão das evidências encontradas (VIEIRA et al., 2010, 2013; MEL0, 2015).

A UC de Estágio Profissional de 50 unidades de crédito (ECTS) tem como objetivo geral que os alunos concretizem a Prática de Ensino Supervisionada em $1^{\circ} \mathrm{CEB}\left(1^{\circ}\right.$ semestre) e em $2^{\circ}$ CEB nas áreas de Português, História e Geografia de Portugal $\left(2^{\circ}\right.$ semestre). ${ }^{8}$ A UC integra dois módulos relativos à prática pedagógica (Observação de Aulas e Desenho do Projeto; Intervenção Pedagógica) e módulos de apoio à prática (Contextos e Recursos Educativos; Psicologia cognitiva da leitura e da escrita). Essa UC visa como resultados de aprendizagem:

a) problematizar contextos, discursos, conteúdos, recursos e estratégias da educação no $1^{\circ}$ Ciclo do Ensino Básico (EB) e de Português e História e Geografia no 2. ${ }^{\circ}$ Ciclo do EB, articulando referentes conceptuais, metodológicos e axiológicos relevantes à sua compreensão;

7 Isto no que diz respeito ao Mestrado em Ensino do $1^{\circ}$ CEB e de Português e História e Geografia de Portugal do $2 .^{\circ}$ CEB, e será neste que nos iremos centrar por ser neste que temos tido a maior orientação dos estagiários e que na secção seguinte serão apresentados os relatórios de estágios que orientei desde 2011.

8 Isto no que diz respeito ao Mestrado em Ensino do $1^{\circ}$ CEB e de Português e História e Geografia de Portugal do $2 .^{\circ} \mathrm{CEB}$, e será neste que nos iremos centrar por ser neste que temos tido a maior orientação dos estagiários e que na secção seguinte serão apresentados os relatórios de estágios que orientei desde 2011. 
b) concretizar, ao nível da concepção, desenvolvimento e avaliação, projetos de intervenção pedagógica para o $1 .^{\circ}$ ciclo do EB e para Português e História e Geografia no $2^{\circ}$ Ciclo do EB, em articulação com as variáveis situacionais específicas dos contextos da prática profissional;

c) mobilizar competências disciplinares, pedagógicas e investigativas relevantes à consecução de projetos de intervenção pedagógica no $1^{\circ}$ ciclo do EB e em Português e História e Geografia no 2. ${ }^{\circ}$ Ciclo do EB;

d) mobilizar competências de reflexividade, criatividade e inovação, no quadro de uma orientação indagatória e colaborativa do processo de desenvolvimento pessoal e profissional.

0 módulo de Intervenção Pedagógica (Estágio) é desenvolvido em Escolas do 1. ${ }^{\circ}$ CEB (no $1 .^{\circ}$ semestre) e do $2^{\circ} \mathrm{CEB}$ (no $2^{\circ}$ semestre), que estabeleceram protocolos de colaboração com a UM. Os estagiários devem envolver-se na observação das práticas pedagógicas dos colegas do mesmo núcleo (escola), preparar e desenvolver um conjunto de aulas/práticas educativas nas áreas de docência em que ficarão profissionalizados $\left(1 .^{\circ} \mathrm{CEB}\right.$ e $\left.2 .^{\circ} \mathrm{CEB}\right)$, planeando-as e discutindo-as em reuniões semanais com os Supervisores (professores da universidade que lecionam as Didáticas Específicas) e com os Orientadores cooperantes que os observarão. 0 número médio de horas semanais das atividades realizadas nas escolas pelos estagiários varia em função das horas de estágio previstas nos planos de estudos de cada Mestrado e das condições concretas da distribuição horária de cada escola/professora cooperante, nunca sendo menos de 15 horas por semana. 0 s professores estagiários devem também participar em atividades extracurriculares organizadas na escola e elaborar ao longo do ano um portefólio que retrate o seu processo formativo nos diversos componentes do Estágio (Regulamento do Estágio dos Mestrados em Ensino, UM, 2011, Art. 14, adapt.). É também sua obrigação elaborar e implementar o PIPS no âmbito da sua prática pedagógica e que será implementado durante o seu estágio e produzido no final o relatório de estágio (VIEIRA et al., 2013; MEL0, 2015).

A profissionalização culmina com a realização do estágio supervisionado, de um portfólio reflexivo elaborado ao longo do ano e com a defesa de um relatório final defendido em provas públicas. A classificação final integra todos os módulos da UC de Estágio Profissional em que se inclui a prática de ensino supervisionada e o relatório final. Determina-se, ainda, que a avaliação da unidade curricular referente à prática de ensino supervisionada "assume um lugar especial na verificação da aptidão do futuro professor para satisfazer, de modo integrado, o conjunto das exigências que the são colocadas pelo desempenho docente no início do seu exercício." (PORTUGAL, 2007). 
Na Universidade do Minho, no âmbito dos vários mestrados, o desenho do modelo de estágio que foi elaborado "procurou criar condições para que a investigação pudesse ocupar um lugar de relevo na prática e na elaboração do relatório, no quadro de uma formação reflexiva" e onde se prevê uma articulação estreita entre a prática pedagógica e o relatório final, ambos focados num "projeto de intervenção pedagógica supervisionada" que articula investigação e ensino (VIEIRA et al., 2013, p. 2644) .

Embora o professor estagiário seja também um mestrando (diferente dos mestrados académicos), pretende-se que desenvolva competências profissionais, mas também investigativas, que interelacione a prática com a investigação. Neste sentido, o professor será também um investigador social, que procura analisar e refletir sobre o processo de aprendizagem dos alunos, no sentido de analisar como os alunos pensam em termos cognitivos e como aprendem, visando constantemente melhorar as suas estratégias e práticas pedagógicas.

0 professor assume o papel de facilitador, permitindo aos alunos ter um maior domínio da construção das suas ideias. Assim, deverá colocar situações desafiantes que favoreçam a compreensão dos alunos, dando a entender a eles que existe alguma contradição entre as suas conceções e os modelos cientificamente aceites, de forma a abalar as suas estruturas cognitivas e formar conhecimento. Neste cenário, a aprendizagem resulta de conflitos cognitivos entre aquilo que o aluno sabe e os novos conhecimentos, dando lugar a novas representações da realidade. É importante ter sempre em conta as ideias dos alunos, tanto as conceções iniciais (prévias) quanto as que se formam com o processo de aprendizagem.

Na formação ministrada privilegiamos o paradigma construtivista, operacionalizado no modelo de aula-oficina (BARCA, 2004), que concebe a aula com ênfase no levantamento das ideias dos alunos. Estas ideias, mais vagas ou precisas, próximas das conceções científicas, ou não, são trabalhadas nos momentos seguintes da aula, por meio da proposta de tarefas que promovam desafios cognitivos. Neste modelo de aula construtivista, valorizam-se os conhecimentos prévios dos alunos, atribui-se relevância à mobilização de conhecimentos em contextos diversos e considera-se a avaliação sistemática das aprendizagens fundamental para que se possa avaliar a progressão das ideias dos alunos. É segundo este modelo pedagógico de formação de professores que a Universidade do Minho tem se pautado nas últimas décadas e reforçado com a implementação do modelo de Bolonha desde 2008/09.

Na secção seguinte serão apresentados alguns desses projetos de investigação que foram realizados durante o estágio profissional e deram origem a relatórios de estágio, em que a articulação entre a prática e a investigação é bem evidente no ensino da História. 


\section{A RELAÇÃO ENTRE A TEORIA E A PRÁTICA NA FORMAÇÃO DOS PROFESSORES: PROJETOS INUESTIGATIUOS EM CONTEXTO DE ESTÁGIO}

Em seguida apresentam-se alguns projetos investigativos implementados em contexto de estágio com alunos do $1^{\circ}$ e do $2^{\circ}$ CEB, centrados em conceitos de segunda ordem/metahistóricos, como o de mudança, tempo, narrativa, significância, evidência histórica, evidência patrimonial e consciência histórica.

Com o objetivo de compreender o papel da investigação no estágio, analisamos um corpus de 14 relatórios, que orientamos de 2011 a 2017 no Mestrado em Educação Préescolar e Ensino do 1. ${ }^{\circ}$ Ciclo do Ensino Básico e no Mestrado em Ensino do $1^{\circ}$ CEB e do 2. CEB, e a partir de 2016-2017 no Mestrado em Ensino do 1. CEB e Ensino de Português e História e Geografia de Portugal. Os alunos destes mestrados podem escolher a área em que pretendem realizar o seu Projeto de Intervenção Pedagógica (PIPS), assim, ao longo deste período, orientamos 15 projetos, sendo 14 relacionados com a Educação Histórica, organizados por temáticas que classificamos em três categorias: Narrativas, Educação Patrimonial e Tecnologia de Informação e Comunicação (TIC) e Conceitos Metahistóricos (Quadro 1).

Quadro 1 - Temáticas dos Relatórios de Estágio do Mestrado em Ensino do 1. e 2. CEB (2011-2017) (N = 14)

\begin{tabular}{|l|l|c|}
\hline \multicolumn{1}{|c|}{ Temáticas } & \multicolumn{1}{|c|}{ Descritores } & N. \\
\hline Narrativas & $\begin{array}{l}\text { Todos os projetos cujo foco é leitura e interpretação pelos alunos de fontes de natureza } \\
\text { verbal escrita ao nivel da literatura, como contos, mitos, lendas, literatura infantil histórica, } \\
\text { banda desenhada, etc. Incluem-se também projetos que versam a expressão escrita dos } \\
\text { alunos (narrativas, textos dramático, construção de BDs). }\end{array}$ & 4 \\
\hline $\begin{array}{l}\text { Educação } \\
\text { patrimonial } \\
\text { e TIC }\end{array}$ & $\begin{array}{l}\text { Todos os projetos cujo foco se relaciona com a educação patrimonial, versando sobre } \\
\text { monumentos, sítios patrimoniais ou objetos, visitas de estudo, quer in loco quer virtual } \\
\text { com recurso a TIC (Google maps e/ou geocaching) para desenvolver o pensamento } \\
\text { histórico, relacionando com conceitos metahistóricos como evidência histórica, significância } \\
\text { histórica e consciência histórica. }\end{array}$ & 4 \\
\hline $\begin{array}{l}\text { Conceitos } \\
\text { metahistó- } \\
\text { ricos }\end{array}$ & $\begin{array}{l}\text { Todos os projetos cujo foco se relaciona com os conceitos metahistóricos: mudança, } \\
\text { tempo, evidência, significância, explicação histórica, causalidade e consciência histórica, } \\
\text { com recurso à exploração de fontes diversas, como linhas de tempo, genealogias, objetos, } \\
\text { imagens, fotografias, cartoons, documentos escritos, etc. }\end{array}$ & 6 \\
\hline Total & \multicolumn{1}{|c|}{6} & 14 \\
\hline
\end{tabular}

Fonte: o autor. 


\subsection{ESTUDOS SOBRE O USO DE NARRATIUAS}

Nas últimas décadas, vários estudos internacionais e nacionais têm demostrado a relevância do uso de narrativas e, em particular, de obras de literatura infantil de ficção histórica, lendas, contos e Banda Desenhada Histórica, como recurso para o ensino e aprendizagem de História, por se revelar uma estratégia adequada e facilitadora de compreensão da História, uma vez que estas apresentam uma linguagem mais acessível e um enredo que promove uma contextualização histórica.

Reis (2013), no seu projeto de relatório, procurou, na sua investigação abordar, analisar e estudar essa temática em torno do uso da narrativa na sala de aula, com enfoque na utilização da literatura de ficção histórica, tendo como título do seu projeto: $A$ literatura de ficção histórica para a construção do conhecimento histórico, implementado em duas turmas, uma do $4^{\circ}$ ano ( 25 alunos) e outra do $6^{\circ}$ ano ( 25 alunos). Procurou perceber de que forma a literatura de ficção histórica contribui para a construção do conhecimento histórico do aluno e, para isso, realizou um conjunto de atividades partindo da interpretação e da exploração das narrativas ficcionais: Era uma vez um rei conquistador, de José Jorge Letria, para trabalhar a temática da formação de Portugal para $\circ 4^{\circ}$ ano e 0 Tesouro, de Manuel António Pina ( $6^{\circ}$ ano) para a temática do Estado Novo e 25 de abril. Concluiu que os alunos dos dois ciclos $\left(1^{\circ}\right.$ e $\left.2^{\circ}\right)$ constroem conhecimento histórico por meio da exploração de obras literárias de ficção histórica, distinguindo nestas o ficcional do real e integrando significativos contributos dessas obras nas suas narrativas, não substituindo, no entanto, as evidências produzidas a partir do cruzamento de outras fontes diversas. As obras de ficção histórica revelaram-se recursos importantes na construção do conhecimento histórico.

Nessa mesma área de investigação em torno do uso da narrativa para aprender História orientamos o projeto de Machado (2014) intitulado 0 potencial didático das narrativas (lendas, mitos e literatura infantil mito-simbólica) para o desenvolvimento do conhecimento e da compreensão histórica nos alunos do $1^{\circ}$ e $2^{\circ}$ ciclo. Nesse estudo, realizado com alunos do $4^{\circ}$ ano (25 alunos) e do $6^{\circ}$ ano (25 alunos) de escolas urbanas de Braga (Portugal), por meio de uma metodologia de investigação-ação, procurou a professora-investigadora analisar de que forma as narrativas, mais propriamente as lendas, os mitos e a literatura infantil mito-simbólica, contribuem para o desenvolvimento da compreensão histórica em alunos do $1^{\circ}$ e $2^{\circ}$ ciclos, promovendo a construção de conhecimento histórico. A partir das narrativas produzidas pelos alunos, procurou analisar a influência desse gênero literário nas suas construções, por meio da identificação de elementos ficcionais presentes nas suas narrativas, em articulação com informação histórica, resultante do cruzamento com outras fontes textuais. A professora-investigadora procedeu à realização de diversas atividades que integraram a exploração de lendas e narrativas mito-simbólicas, tendo selecionado para o $1^{\circ}$ 
ciclo a Lenda do Milagre de Ourique (versão de Gentil Marques), conteúdo inserido no tema da "Formação de Portugal"; e para o $2^{\circ}$ ciclo a obra História de uma flor, de Matilde Rosa Araújo, considerada literatura infantil de forte pendor mito-simbólico pela temática abordada, relacionada com o cravo e a sua associação ao 25 de abril, tema lecionado durante a intervenção pedagógica no $2^{\circ}$ ciclo. Conclui com o seu projeto que os alunos são capazes de construir o seu conhecimento histórico com recurso a esse tipo de narrativas (lendas e narrativas mitológicas), sendo capazes de distinguir o real do ficcional pelo confronto com outras fontes, sendo, no entanto, para isso, imprescindivel a consulta e o cruzamento com outras fontes histórica e historiográficas.

0 projeto de Filipe (2017) intitulado As lendas, mitos e tradição oral como recurso pedagógico no processo de construção do conhecimento histórico, na mesma linha de investigação, procurou analisar como alunos do $1^{\circ}$ Ciclo (26 alunos do $2^{\circ}$ ano) e do $2^{\circ}$ Ciclo (27 alunos do $5^{\circ}$ ano) desenvolvem o seu processo de construção do conhecimento histórico tendo por base a exploração de ferramentas didáticas como lendas, mitos e tradição oral, bem como perceber de que forma estes recursos abonam um processo de ensino-aprendizagem construtivista, segundo o modelo de aula-oficina. No $1^{\circ}$ ciclo, mediante uma série de atividades diversificadas e integradoras, levou os alunos a explorar lendas (duas versões diferentes da lenda dos batizados da meia-noite, lenda tradicional de Ponte da Barca), identificando convergências e divergências, bem como o contacto com fontes patrimoniais locais relacionadas com as lendas exploradas. № $2^{\circ}$ ciclo, subordinado ao tema "Os efeitos da expansão marítima", os alunos exploraram a lenda do Caramuru e o mito 0 Adamastor. Constatou que os alunos do $1^{\circ}$ ciclo são mais recetivos à exploração e interpretação desse tipo de instrumentos, pela reflexividade, criatividade e empatia histórica que estes thes proporcionam. Relativamente aos alunos do $2^{\circ}$ ciclo, embora tenham realizado aprendizagens significativas, revelaram-se menos reflexivos e críticos, pouco habituados a explorar instrumentos pedagógicos desta natureza.

Visando explorar as potencialidades de outro género literário para a aprendizagem da História, Cardoso (2016), no seu projeto intitulado A Banda Desenhada histórica como recurso e fonte historiográfica para o ensino e aprendizagem da História: um estudo com alunos do $1^{\circ}{ }^{\circ}$ e $2 .^{\circ}$ ciclo do E.B, implementado numa turma do $4^{\circ}$ ano (26 alunos) e numa turma do $6^{\circ}$ ano (24 alunos), pretendeu desenvolver um conjunto de atividades ligadas à exploração de $\mathrm{BD}$ e posterior construção de uma $\mathrm{BD}$ pelos alunos. Com este projeto procurou promover nos alunos a leitura e interpretação deste género literário, a produção de inferências e deduções, a procura da objetividade e a evidência histórica, cruzando a informação recolhida com outras fontes históricas e historiográficas. A concretização desde projeto incidiu sobre a utilização da Banda Desenhada histórica como recurso pedagógico e fonte historiográfica para o ensino e aprendizagem da História, no $1^{\circ}$ Ciclo sobre a temática "Expansão marítima portuguesa” e no $2^{\circ}$ Ciclo sobre o “0 25 de abril de 1974 e o regime democrático". Para a 
abordagem desses temas, no $1^{\circ}$ Ciclo deu destaque para a problemática da chegada dos portugueses ao Brasil "Descoberta/Achamento", selecionando excertos de dois álbuns de BD, o primeiro de autores portugueses e o segundo de autores brasileiros. № $2^{\circ}$ ciclo exploraram excertos de duas $\mathrm{BDs}$ sobre a temática do 25 de abril. Esse projeto demonstrou a relevância da utilização de $\mathrm{BD}$ em sala de aula para a aprendizagem de História, contribuindo para o desenvolvimento da compreensão histórica nos alunos e de outras competências específicas, como a leitura e a interpretação de fontes diversas e com mensagens divergentes, bem como competências transversais, ao nível da comunicação (área do Português e da Expressões).

\subsection{ESTUDOS COM EXPERIÊNCIAS EM TORNO DO PATRIMÓNIO E RECURSO ÀS TECNOLOGIAS}

Uma nova linha de investigação, que articula educação histórica e educação patrimonial, tem vindo a desenvolver-se e a afirmar-se. Na Universidade do Minho, vários estudos realizados sob orientação de lsabel Barca têm contribuído para a investigação nesse âmbito, em que se destaca o estudo de Pinto (2011). Nos últimos anos temos vindo a fomentar o estreitar de laços epistemológicos e empíricos, por meio da orientação de vários relatórios de mestrado, bem como pela organização de vários Seminários em Educação Patrimonial l, II e III dos quais resultou a publicação de dois livros em formato e-book (SOLÉ, 2014a, SOLÉ 2015), os quais foram realizados em parceria com a Câmara Municipal de Braga e que se encontram já na sua terceira edição, realizada em janeiro de 2016.

Alguns destes estudos em cognição histórica situada, em que se procura analisar as ideias dos alunos a partir de experiências pedagógicas em torno do património, em contexto formal ou informal, direto ou virtual, têm demonstrado que estas experiências e estudos têm reforçado a articulação entre história, património e as novas tecnologias. Nesta linha de investigação, apresentamos quatro estudos que orientamos no Mestrado em Ensino do $1^{\circ} \mathrm{e}$ $2^{\circ}$ CEB e cujas temáticas se relacionam com o património e a articulação entre a educação histórica e a educação patrimonial, e três deles com as novas tecnologias.

A investigação que Almeida (2014) realizou em contexto de intervenção pedagógica supervisionada, enquadra-se nesta tipologia de estudos com recurso a fontes patrimoniais intitulado 0 património histórico como estratégia pedagógica para a construção do conhecimento histórico. Este projeto foi desenvolvido numa turma do $3^{\circ}$ ano (25 alunos) e numa turma do $5^{\circ}$ ano (25 alunos), em duas escolas do centro urbano de Braga. Este projeto debruçou-se sobre o estudo do património histórico de Braga, procurando a professorainvestigadora analisar como o património local poderá constituir um recurso e uma estratégia 
pedagógica para a construção do conhecimento histórico. Procurou responder às seguintes questões de investigação: "Quais as potencialidades do estudo do património histórico como estratégia pedagógica para a construção do conhecimento histórico?", "Que conhecimentos os alunos constroem a partir do estudo do património histórico locale" e "Que fontes os alunos consideram mais relevantes e valorizam no estudo da História Locale".

No $3^{\circ}$ ano $\left(1^{\circ} \mathrm{CEB}\right)$, Almeida (2014) preparou uma visita de estudo a um conjunto de fontes patrimoniais de Braga previamente selecionadas pelos alunos: Palácio do Raio; lgreja dos Congregados; Torre de Menagem; Capela de S. Geraldo (onde ouviram o podcast); Sé de Braga; e Convento do Pópulo Termas Romanas do Alto da Cividade. A análise dos dados da implementação do projeto no $1^{\circ}$ ciclo ( $3^{\circ}$ ano) permitiu concluir que os alunos em contacto direto com fontes patrimoniais operam por níveis diferenciados de evidência histórica e de significância histórica, mobilizando conhecimentos prévios e históricos. Revelaram níveis de significância histórica bastante sofisticados, atribuindo significância ao património local, nos níveis objetivista básica e objetivista sofisticada, procedendo a argumentações e generalizações.

No $5^{\circ}$ ano $\left(2^{\circ}\right.$ ciclo), a autora procurou averiguar como os alunos exploram fontes patrimoniais locais in situ e nacionais virtualmente (visita virtual ao Mosteiro dos Jerónimos) relacionadas com o estilo Manuelino. Para além dos conceitos estruturais de evidência e significância, foi dado enfoque a conceitos substantivos relacionados com a temática/época em estudo (Manuelino, Descobrimentos e Expansão ultramarina). A análise das respostas dos alunos a um guião-questionário aplicado durante a visita a vários monumentos/construções e objetos do estilo manuelino em Braga (Casa dos Coimbrã; na Sé de Braga, a pia batismal e a abóbada de cruzaria; no Museu Tesouro da Sé, a cruz da primeira missa no Brasil, aquando da chegada de Pedro Álvares (abral) permitiu constatar que os alunos tendem a realizar uma descrição simples da fonte patrimonial, mas revelam competências de mobilização de conhecimentos históricos e artísticos do Manuelino. A nível da significância histórica, as respostas dos alunos têm particular incidência em duas categorias, a de consciência de um passado simbólico (quatro alunos em 25) e consciência de relação passado-presente (quatro alunos em 25). Este projeto permitiu evidenciar que estes alunos apresentam nas suas respostas vários níveis de progressão do seu pensamento histórico tendo por base a evidência e a significância histórica, destacando, assim, o desenvolvimento de uma consciência histórica e patrimonial de interesse turístico (como veículo de atração turística), de um passado monumental, de um passado simbólico e da relação passado-presente.

Um outro estudo, original pela temática escolhida - o azulejo - foi o projeto desenvolvido por Nunes (2015) intitulado Azulejaria Portuguesa e a Valorização do Património: Interpretação de Fontes Patrimoniais lconográficas por Alunos do $1^{\circ}$ e $2^{\circ}$ Ciclo do Ensino Básico, que visou analisar as conceções de crianças sobre consciência história e patrimonial a partir do uso de fontes patrimoniais, com destaque para o património azulejar. Este projeto 
foi implementado em duas escolas urbanas de Braga, uma do $1^{\circ} \mathrm{CEB}$, do $3^{\circ}$ ano, constituída por 25 alunos (oito a nove anos) e uma turma do $2^{\circ}$ CEB e uma do $5^{\circ}$ ano, constituída também por 25 alunos (10 a 11 anos). Este estudo, inovador e bastante original, por se centrar no azulejar como fonte patrimonial, procurou responder às seguintes questões de investigação: "Como interpretam os alunos a evidência nos painéis de azulejo?" e "Que valor atribuem ao azulejar no contexto do património local e nacional e que eventual relevância teve este projeto nessa valorização?". Pretendeu a professora-investigadora perceber nos alunos, perante este tipo de fonte patrimonial, bem presente na Cidade de Braga, associada ao Barroco, que tipo de inferências e deduções realizam, que relações estabelecem com os conhecimentos históricos que possuem, que consciência patrimonial manifestam e como esta pode se desenvolver por meio de um projeto dessa natureza. № $3^{\circ}$ ano os alunos contactaram com fontes patrimoniais azulejares de Braga, na visita de estudo a vários monumentos barrocos com painéis de azulejos (Capela de S. Geraldo e Pópulo). № $5^{\circ}$ ano os alunos exploraram quatro painéis de azulejos (Ala dos namorados; Batalha de Aljubarrota; Casamento de D. João I e Filipa de Lencastre; a Padeira de Aljubarrota), cruzando as leituras desses painéis de azulejos com a interpretação de outras fontes icónicas alusivas às mesmas temáticas. Este estudo permitiu concluir que o uso desta tipologia de fonte patrimonial (o azulejo) no ensinoaprendizagem de História contribui para a promoção de competências de literacia visual, para a construção de pensamento eminentemente histórico, como meio de aprendizagens significativas de conteúdos de História e de outras áreas como a Matemática e as Expressões Visuais, surgindo como instrumento didático e/ou tema transversal potenciador de um ensino interdisciplinar e abrangente e de uma consciência histórica, patrimonial e cívica emergente.

Em 2017, orientamos o projeto de João Pinheiro intitulado Visita de Estudo Virtual versus Visita de Estudo in Loco: contributos para aprendizagem de História no $1 .^{\circ}$ e $2 .^{\circ}$ Ciclo do Ensino Básico, tendo como principal objetivo compreender de que forma as crianças constroem conhecimento histórico, tendo como estratégia a exploração do património local e nacional, por meio de visitas de estudo virtuais (VEV) e visitas in loco. Procurou o professorinvestigador explorar as potencialidades e as diferenças entre a utilização destas duas estratégias, a partir da visita virtual e in loco ao Castro de S. Lourenço, em Esposende (Norte de Portugal), por uma turma de $3^{\circ}$ e $4^{\circ}$ anos (9 alunos), e no $5^{\circ}$ ano (21 alunos) exploraram vários monumentos nacionais de estilo Manuelino por meio da Visita de Estudo Virtual (VEV). Concluiu com este estudo que o ensino da História beneficia do recurso a atividades inovadoras, de cariz construtivista, evidenciando-se as potencialidades das visitas de estudo (virtuais ou in loco) para fomentar aprendizagem da História e o pensamento histórico dos alunos, embora tenha identificado diferenças ao nível da produção de conhecimento histórico, revelando-se mais significativo no contacto direto com as fontes patrimoniais. 0 professorinvestigador reforça a ideia de Manique e Proença (1994) ao afirmar não é o património que tem de ir à escola, mas sim a escola que deve ir ao encontro do património, mas para isso, 
no caso da Visita de Estudo "in loco", pela sua complexidade exige uma preparação prévia exaustiva que vai desde a burocracia à planificação da atividade, que incluí a elaboração de guiões-questionários e avaliação das aprendizagens através de ficha metacognitiva.

Partindo da história local, aliada ao uso das novas tecnologias, nomeadamente o recurso ao Google maps e Geocaching, Cunha (2016) realizou um projeto intitulado As novas tecnologias no ensino/aprendizagem da história: uso do Google maps e Geocaching por alunos do $1 .^{\circ}$ e $2^{\circ}$ Ciclo do Ensino Básico, desenvolvido numa turma do $2^{\circ}$ ano (19 alunos) e numa turma do $6^{\circ}$ ano (23 alunos). Procurou o investigador analisar: a) as potencialidades do uso das novas tecnologias no processo de ensino/aprendizagem da história; b) que conhecimentos históricos e competências históricas potencia o uso do Geocaching como estratégia de ensino; e c) como avaliam, os alunos, os conhecimentos históricos adquiridos a partir desta estratégia com recurso às novas tecnologias, em concreto com o uso do Google maps e Geocaching. Para a sua concretização, o professor-investigador realizou estratégias que envolveram o trabalho individual e cooperativo, nomeadamente o preenchimento de um questionário diagnóstico, a determinação de itinerários e a localização de diversos locais através do Google maps (relacionados com instituições locais de Braga), a construção de geocaches, a criação de roteiros de Geocaching, prática do Geocaching e o preenchimento de uma ficha de metacognição. Este estudo permitiu concluir que a exploração do Google maps e o Geocaching são atividades que possibilitam aos alunos, além de uma nova aventura e descoberta, uma melhor compreensão do espaço que os rodeia e assimilação dos conteúdos teóricos por meio da tecnologia. São atividades pedagógicas com mais-valias para o contexto educativo pois potenciam o desenvolvimento de aprendizagens significativas no âmbito da consciência e do pensamento histórico, promovendo, ainda, a evolução da literacia digital dos alunos.

\subsection{ESTUDOS RELACIONADOS COM CONCEITOS METAHISTÓRICOS (MUDANÇA, TEMPO, EUIDÊNCIA, SIGNIFICÂNCIA, EXPLICAÇÃO, CAUSALIDADE, CONSCIÊNCIA HISTÓRICA...)}

De acordo com a epistemologia da Educação Histórica e segundo Barca e Solé (2012), ensinar e aprender História não se pode cingir apenas a possuir um dado conhecimento histórico (conceitos substantivos), que é importante e indispensável - não é isso que está em causa -, mas é essencial também dominar um conjunto de competências ao nível da capacidade de selecionar, analisar, interpretar fontes, estabelecer relações de causalidade, explicar historicamente, ser capaz de construir relatos/narrativas, orientar-se temporalmente, ou seja, saber aplicar noções que representam a natureza da História, que constituem, segundo a terminologia de Lee (2001), 
conceitos de segunda ordem, estruturais e mais recentemente denominados de metahistóricos. Descrevem-se a seguir vários estudos que procuram analisar como os alunos dos anos iniciais estruturam o pensamento histórico, incidindo sobre conceitos metahistóricos de tempo, mudança, evidência histórica e significância histórica.

0 projeto de Costa (2019), intitulado $A$ compreensão do tempo para o desenvolvimento do pensamento histórico: um estudo com alunos do $1^{\circ} \mathrm{e} 2^{\circ} \mathrm{Ciclo}$ do Ensino Básico, foi implementado numa turma do $2 .^{\circ}$ ano (19 alunos) e numa turma do $6 .^{\circ}$ ano (23 alunos), por meio de uma abordagem pedagógica e investigativa. A professora-investigadora visa com este projeto debater a compreensão do tempo para o desenvolvimento do pensamento histórico, incidindo no tempo do relógio, no tempo do calendário, no tempo histórico e no conceito de mudança. Para a sua implementação no $2^{\circ}$ ano, realizou atividades diversificadas que promoveram o estudo das unidades de medida de tempo, do tempo do relógio, do tempo do calendário, do passado pessoal e, por fim, do passado mais longínquo, relacionado com o tempo histórico. No $6 .^{\circ}$ ano a abordagem do conceito de tempo e de mudança esteve subordinado à temática “0 25 de abril de 1974 e o regime democrático". 0 projeto procurou analisar como os alunos constroem noções de tempo físico ao nível do sistema convencional de medição do tempo (tempo do relógio, tempo do calendário); que conceções de mudança evidenciam perante atividades de sequencialização de acontecimentos históricos (linhas de tempo; ordenação de imagens); e que competências desenvolveram ao nível da compreensão da temporalidade a partir de atividades desafiadoras. Os resultados da análise dos dados permitiram concluir que um ensino explícito em torno do conceito de tempo favorece a compreensão temporal dos alunos, no entanto este é um conceito complexo, que necessita de uma prática sistemática. Salienta a professora-investigadora que é importante, neste tipo de atividades de promoção da compreensão temporal, não deixar de atender à orientação temporal, sendo fundamental interligar os três tempos que se cruzam na nossa vivência (passado, presente e futuro), pois o passado ajuda a entender o presente, mas só perspetivando o futuro poderemos formar cidadãos críticos e ativos, que possam participar e agir na sociedade.

Articulando a História com a Matemática, Oliveira (2016), no seu projeto intitulado A compreensão do tempo e o desenvolvimento da competência da temporalidade em História em articulação com a Matemática em alunos do $44^{\circ}$ ano, procurou promover numa turma do $4 .^{\circ}$ ano (20 alunos) aprendizagens ao nível do tempo, da compreensão temporal e do tempo histórico. Através do seu estudo, visou analisar as conceções, os conhecimentos e as competências que os alunos detêm ao nível da temporalidade; averiguar como os alunos constroem e desenvolvem a compreensão do tempo e da temporalidade em História em articulação com a Matemática (raciocínio lógico-matemático) a partir de atividades desafiadoras e problematizadoras; e que competências ao nível da compreensão da temporalidade desenvolveram os alunos a partir das atividades desafiadoras e problematizadoras que visaram articular a História e a Matemática. Concluiu que esse grupo de alunos evidenciou 
no início do projeto graves lacunas no que concerne ao tempo e à temporalidade em História, tendo-se verificado com a sua implementação um grande progresso ao nível da capacidade de sequencialização de acontecimentos num friso cronológico e de interpretação do mesmo, bem como na compreensão do conceito de duração, que implicava raciocínio lógico-matemático. Constatou que os alunos demonstraram grandes dificuldades na construção de linhas do tempo, superadas paulatinamente ao longo do projeto. Constatou, também, que a conceção e a compreensão de conceitos como o tempo e o tempo histórico, bem como de outros conceitos que thes são associados são desenvolvidas de forma gradual, e a necessidade de um ensino contínuo e sistemático é relevante para a apropriação destes conceitos, que são fundamentais para a compreensão histórica. Reforça a ideia que as competências ao nível da temporalidade revelam-se essenciais para que os alunos sejam capazes de perceber o passado, relacioná-lo com o presente e projetar o futuro.

0 estudo de Cardoso (2013), integrado no seu projeto de relatório de estágio, incidiu sobre os conceitos de evidência e de mudança. A partir da temática da alimentação, procurou perceber como alunos do $3 .^{\circ}$ ano ( 16 alunos) de uma escola peri-urbana de Braga lidam com estes conceitos de segunda ordem, e que ideias históricas veiculam a partir da interpretação de várias fontes icónicas e textuais relacionadas com o tema da alimentação. Para responder à seguinte questão de investigação: "como constroem os alunos o conhecimento e a sua aprendizagem partindo da utilização/exploração de fontes diversas?", realizou um conjunto de tarefas: Tarefa 1: pesquisa sobre receitas tradicionais relacionadas com a temática da alimentação; Tarefa 2: "A Origem e Localização dos Alimentos"; Tarefa 3: "Os Meios de Transporte, a sua evolução e o seu papel na mudança de hábitos alimentares"; Tarefa 4: "A evolução da alimentação"; e Tarefa 5: "Feiras e mercados ao longo dos tempos". Os dados permitiram identificar quatro níveis de categorias subordinados ao conceito de evidência histórica relacionada com a leitura e interpretação de fontes diversas (icónicas e textuais) relacionada com a Tarefa 2 - Origem e localização dos alimentos: 1) Inferências só a partir de fontes textuais: as crianças apenas se fundamentaram nas fontes textuais para responder à questão; 2) Descritiva simples: a partir da fonte icónica na qual as crianças usaram apenas um ou dois pormenores nas suas descrições; 3) Descritiva pormenorizada: a partir da fonte icónica quando para descrever uma imagem eram capazes de usar três ou mais pormenores; 4) Inferência cruzada: as crianças utilizaram informação retirada tanto das fontes icónicas quanto das textuais para criarem a sua resposta. Numa outra tarefa os alunos responderam à seguinte questão: Porque achas que, ao longo dos tempos, a alimentação das pessoas foi sofrendo alterações? Justifica a tua resposta. Este estudo demonstrou que os alunos tendem a descrever a mudança histórica como um processo linear, sugerindo que o desenvolvimento se processa numa sequência progressiva, muito embora alguns reconheçam já a diversidade na mudança ao nível da alimentação. 
Na mesma linha de investigação, subordinado aos conceitos metahistóricos de evidência histórica e mudança, inspirado nos estudos de Solé (2009), surge o projeto de relatório de estágio de Pimentel (2013) intitulado 0 desenvolvimento da compreensão histórica através de uma abordagem de aprendizagem cooperativa: um projeto com alunos do $3 .^{\circ}$ ano do Ensino Básico. Implementado na mesma turma do projeto anterior, com os mesmos 16 alunos, a professora-investigadora estagiária procurou investigar como se processa a compreensão histórica, centrada nos conceitos de evidência e de mudança, numa abordagem de aprendizagem cooperativa. Através da metodologia de investigação-ação a professora procurou trabalhar a temática do comércio, realizando, para isso, um conjunto de tarefas que visaram trabalhar com os alunos a comparação do comércio no passado e no presente e a evolução dos mercados e feiras. Realizou várias tarefas com imagens de feiras e mercados de diversas épocas (Mercado Romano; Feira Medieval; Feira do Séc. XVIII; Feira do Séc. XIX; Feira dos anos 50 e Feira atual), nomeadamente exploração de imagens e sequencialização de imagens do mais antigo para o mais recente. Algumas conclusões do seu projeto:

a) na sequencialização proposta pelos grupos, atenderam mais ao suporte material da fonte (cor ou preto e branco) do que à análise do conteúdo;

b) recorreram à cultura material (vestuário das pessoas) e aspetos sociais ("parecem ser príncipes e princesas", "camponeses") para descrever as imagens;

c) a análise das fontes é predominantemente descritiva, enumerando os alunos o que veem nas fontes, no entanto, inferiram qual a atividade comercial representada;

d) introduziram nas suas respostas referenciais temporais (passado/presente, deste tempo/antigamente) quando as comparam;

e) a abordagem cooperativa nos primeiros anos de escolaridade favorece a construção do conhecimento e pensamento histórico, pelos debates e promoção da argumentação.

Ainda sobre o conceito metahistórico de mudança, orientamos o projeto de Moreira (2017) intitulado 0 conceito de mudança em História: conceções de alunos do $1^{\circ}$ e $2 .^{\circ}$ Ciclos do Ensino Básico a partir da exploração de fontes visuais e objetuais. Através deste projeto de investigação-ação, perspetivou a professora-investigadora perceber e aclarar que conceções apresentam os alunos acerca do conceito de segunda ordem - mudança histórica -, recorrendo às fontes visuais e objetuais como ferramentas didático-pedagógicas e analisar 
como práticas de ensino desafiadoras podem contribuir para a estruturação da compreensão da mudança nos alunos. No $1^{\circ}$ ano (21 alunos) de uma escola urbana de Braga, implementou um conjunto de atividades diversificadas e motivadoras que incidiram sobre a mudança orientada para o estudo do passado pessoal e familiar dos alunos: linhas de tempo, árvores genealógica, construção de um museu do brinquedo com objetos da família, brincadeiras de antigamente e de agora. № $2{ }^{\circ}$ CEB o projeto decorreu na disciplina de História e Geografia de Portugal numa turma do $6 .^{\circ}$ ano (25 alunos) numa escola do mesmo agrupamento. 0 projeto foi norteado pelas temáticas relativas ao Estado-Novo, 25 de abril de 1974, regime democrático e Portugal na União Europeia, dando enfoque às mudanças que foram ocorrendo ao longo destes marcos históricos da história nacional. A concretização das intervenções alicerçouse a uma prática de ensino-aprendizagem baseado na investigação-ação e orientado por princípios construtivistas e por práticas sustentadas no modelo aula-oficina. Para a recolha dos dados aplicou diferentes técnicas e instrumentos: o uso de entrevistas semiestruturadas realizadas no início do projeto com recurso a tarefas de ordenação de imagens sobre a temática da família, tarefas de papel e lápis (fichas de trabalho), linhas do tempo, exploração de fontes visuais e objetuais e fichas metacognitivas, privilegiando os diálogos estabelecidos entre aluno-professor e aluno-aluno.

Sobre a concepção de mudança, concluiu que as crianças entre seis e sete anos de idade já reportam algumas ideias acerca da mudança quando falam sobre as imagens que ordenaram e tendem a pensar a mudança como evolutiva, inferindo-lhe linearidade ao longo dos tempos. Os alunos do $6 .^{\circ}$ ano $\left(2{ }^{\circ} \mathrm{CEB}\right)$ associam a mudança maioritariamente ao progresso, à evolução, apesar de já se denotar alguma alusão à mudança como diversidade. Estes resultados estão na mesma linha de outros estudos (BARTON, 2001; SOLÉ, 2009), nos quais entrevistas com recurso à sequencialização de imagens demonstraram que os alunos, dentro dessas faixas etárias (6-7 anos e १1-१३ anos), apontam para a mudança como uma melhoria num crescimento, ou seja, para a mudança como progresso, que as coisas do presente são melhores que as do passado (passado como deficitário), referenciando o melhoramento dos materiais, o aparecimento da tecnologia, mas simplesmente os alunos têm a ideia que as coisas mudam sequencialmente ao longo do tempo. Comprovou a professora-investigadora que a exploração de linhas do tempo e a construção da linha do tempo pessoal a partir da exploração de fotografias dos próprios alunos funcionaram como mediadoras de uma aproximação do passado pessoal dos alunos, permitindo desenvolver o conceito de duração quando apontaram os intervalos de tempo entre as fotografias/ acontecimentos, bem como facultaram uma perceção direta das mudanças neles próprios. No que diz respeito às atividades com fontes objetuais, concluiu que estas se revelaram potenciadoras para a perceção da mudança ao longo dos tempos; como refere Hoodless (1996), o carater tridimensional dos objetos, mais concretamente dos mesmos objetos, mas de épocas díspares, é um potencial didático para a constatação da mudança e de permanências. 
0 projeto de Ramos (2016) intitulado 0 potencial didático da genealogia para a construção da identidade e desenvolvimento da compreensão histórica dos alunos do $1^{\circ} \mathrm{e}$ $2^{\circ}$ ciclo do ensino básico, implementado numa turma do $11^{\circ}$ ano (23 alunos) e, posteriormente, numa turma do $5 .^{\circ}$ ano (23 alunos), pretendeu, fundamentalmente, compreender de que forma a utilização das genealogias como recurso didático pode contribuir para o desenvolvimento da consciência histórica, estando, aqui, indubitavelmente ancorado o desenvolvimento da compreensão temporal e a construção da identidade. Para isso, no $1^{\circ}$ ano implementou um conjunto de atividades orientadas para o estudo da família, visando à construção da identidade pessoal e familiar dos alunos recorrendo à exploração e construção de genealogias em articulação com outros recursos, como linhas de tempo e exploração de fotografias. № $5 .^{\circ}$ ano implementou várias atividades com enfoque na construção da identidade nacional, a partir da exploração e análise das genealogias dos reis correspondentes ao conteúdo programático desenvolvido. Através dos dados recolhidos a partir de vários instrumentos (ficha diagnóstica; tarefas de papel e lápis; registos de observação e diários de aula) e posteriormente analisados de forma indutiva, constatou a investigadora que as crianças do $11^{\circ}$ ano, através das várias atividades realizadas em torno das genealogias, tiveram oportunidade de invocar o passado ao presente através do fenómeno de rememoração (RÜSEN, 2016), tendo sido capazes de ingressar num exercício de retorno ao seu passado próximo, (re)lembrando, ainda que de uma construção simbólica e subjetiva se trate, um período de tempo vivenciado por elas mesmas, ao qual atribuem especial relevância. № $5 .^{\circ}$ ano as genealogias foram utilizadas pelos alunos como plataformas de acesso a um período característico da História do nosso país: a expansão maritima portuguesa, do qual emerge, desde logo, um conjunto de figuras históricas associadas ao nosso imaginário coletivo. Constatou que a aplicação das genealogias neste ano de escolaridade abriu alternativas ao nivel da exploração de fontes que os alunos, geralmente, não estão habituados a explorar e analisar. Verificou que as genealogias dos reis associados à época em estudo permitiram auxiliar os alunos ao nível do reconhecimento das figuras históricas a ela associadas, propiciando o estabelecimento de uma rede de ligação entre as situações ocorridas e o contexto do seu desenvolvimento, acentuando-se uma maior facilidade de ordenação temporal das respetivos factos e acontecimentos. Este projeto permitiu atestar a potencialidade que a utilização das genealogias apresenta ao nível do desenvolvimento da consciência histórica, a qual reivindica, por um lado, a formação da compreensão temporal, e, por outro, o desenvolvimento gradual da identidade, seja ela de cariz pessoal, familiar ou nacional. 


\section{CONSIDERAÇÕES FINAIS}

Os mestrados em ensino da Universidade do Minho preveem a formação do professor/educador como prático reflexivo e intelectual crítico, conferindo um lugar de relevo à investigação pedagógica no estágio através da construção e avaliação de um "projeto de intervenção pedagógica supervisionada" (PIPS), que deve se enquadrar numa visão democrática da educação. Nesta perspectiva, Gago (2018b, p. 509) sustenta que na formação de professores "a universidade e a formação que esta promove, deve, por um lado, fomentar o espírito crítico e de investigação e, por outro, ampliar o seu papel como consultora de investigação e de desenvolvimento de professores." Esta formação está em consonância com o profissionalismo democrático, que no quadro do desenvolvimento profissional do professor é holístico, com uma preocupação humanista. Sustenta-se a "articulação da ação pedagógica-educativa do professor com amplos valores e ideais da sociedade le] a ação deste professor é orientada para a investigação e para salas de aula colaborativas que permitem vivência e experiências democráticas." (GAG0, 2018a, p. 11). No processo de educação-formação é preciso atender às vozes dos alunos e dos professores, numa lógica de envolver quem aprende e fomentar a compreensão de si mesmos como sujeitos de mudança e de transformação (SCHMIDT, 2016).

Os relatórios finais dos professores estagiários realizados no contexto da prática de ensino supervisionado, e que aqui foram analisados, refletem esta complexidade que a formação dos professores implica, as suas tomadas de decisões nas opções metodológicas adotadas, na reflexividade constante, no repensar de estratégias, nos desafios pedagógicos com que se depararam, mas também na capacidade de investigar e refletir sobre os dados recolhidos, visando compreender as ideias dos alunos e como eles pensam historicamente.

A diversidade de estudos empíricos que temos acompanhado e orientado, sustentados pelos pressupostos teóricos e por questões metodológicas da pesquisa empírica sobre ideias históricas de segunda ordem/metahistóricos, como os exemplos que aqui descrevemos, contribui sem dúvida para operar mudanças no ensino de História e são, com certeza, uma mais-valia para a investigação em Educação Histórica em Portugal. Vários dos nossos formandos (ex-alunos estagiários) têm contribuído para efetivar essa mudança nas escolas onde lecionam, chegam-nos ecos do contributo que estes têm operado no sistema educativo nacional, ao nível do ensino da História a crianças e adolescentes, demonstrando o potencial formativo deste modelo que incentiva os docentes a operarem com conceitos metahistóricos e levarem os alunos a pensar historicamente e de forma construtivista, em que o modelo de aula-oficina faz parte da sua prática diária em sala de aula.

Para terminar, desejo apenas realçar que este modelo de formação gerou nos futuros professores competências ao nível da docência e da investigação em Educação 
Histórica, reforçada em várias comunicações e publicações que alguns desses mestres têm apresentado em congressos nacionais e internacionais nos últimos anos, demonstrando a pertinência da relação entre a teoria e a prática ao longo do seu processo de formação, dando a conhecer o trabalho empírico que desenvolveram com os seus alunos em sala de aula. 0 que é mais gratificante é quando nos dizem ao fim de alguns anos: "professora, eu quero continuar a investigar e para isso voltei à Universidade do Minho, para realizar o doutoramento e quero perceber como as metodologias ativas promovidas pelas Tecnologias podem potenciar o desenvolvimento da consciência histórica em alunos do $1^{\circ}$ e 2. ${ }^{\circ}$ CEB." (Vânia, doutoranda da UMinho) (informação verbal).

\section{REFERÊNCIAS}

ALMEIDA, É. 0 património histórico como estratégia pedagógica para a construção do conhecimento histórico. 2014. Relatório de Estágio (Mestrado em Ensino do 1. ${ }^{\circ}$ e 2. ${ }^{\circ}$ Ciclo do Ensino Básico) - Universidade do Minho, Braga, 2014. Disponível em: http://hdl.handle.net/1822/37960. Acesso em: 2 maio 2018.

BARCA, I. Aula Oficina: do projeto à avaliação. In: JORNADAS INTERNACIONAIS DE EDUCAÇÃO HISTÓRICA: PARA UMA EDUCAÇÃO HISTÓRICA DE QUALIDADE, 4., 2004, Braga. Actas [...] Braga: CIED, Universidade do Minho: Instituto de Educação e Psicologia, 2004. p. 131-144.

BARCA, l.; SOLÉ, G. Educación histórica en Portugal: metas de aprendizaje en los primeiros anos de escolaridade. REFFOP, v. 15, n. 1, p. 91-100, 2012. Disponível em: www.aufop.com. Acesso em: 8 jul. 2018.

CARDOSO, A. F. A construção do conhecimento e o desenvolvimento de competências de aprendizagem dos alunos a partir da área de Estudo do Meio (História). 2013. Relatório de Estágio (Mestrado em Educação Pré-escolar e Ensino do 1. ${ }^{\circ}$ ciclo) - Universidade do Minho, Braga, 2013.

CARDOSO, T. A banda desenhada histórica como recurso e fonte historiográfica para o ensino e aprendizagem da História: um estudo com alunos do 1. ${ }^{\circ}$ e 2. ${ }^{\circ}$ Ciclo do E.B. 2016. Relatório de Estágio (Mestrado em Ensino do 1. ${ }^{\circ}$ e 2. ${ }^{\circ}$ ciclo do Ensino Básico) - Universidade do Minho, Braga, 2016. Disponível em: http://hdl.handle.net/1822/45240. Acesso em: 5 jun. 2019.

COLLINGWOOD, R. A ideia de História. 9. ed. Lisboa: Editorial Presença, 2001.

COSTA, A. A compreensão do tempo para o desenvolvimento do pensamento histórico: um estudo com alunos do $1^{\circ}$ e $2^{\circ}$ Ciclo do Ensino Básico. 2019. Relatório de Estágio (Mestrado em Ensino do $1^{\circ}$ e 2. ${ }^{\circ}$ ciclo do Ensino Básico) - Universidade do Minho, Braga, 2019. Disponível em: http://hdll.handle. net/1822/45202. Acesso em: 10 jul. 2019.

CUNHA, C. As novas tecnologias no ensino/aprendizagem da História: uso do Google maps e Geocaching por alunos do $1^{\circ}$ e $2^{\circ}$ Ciclo do Ensino Básico. 2016. Relatório de Estágio (Mestrado em Ensino do 1. e 2. ${ }^{\circ}$ ciclo do Ensino Básico) - Universidade do Minho, Braga, 2016. Disponivel em: http://hdll.handle. net/1822/45203. Acesso em: 5 jun. 2019. 
FLPE, R. As lendas, mitos e tradição oral como recurso pedagógico no processo de construção do conhecimento histórico. 2017. Relatório de Estágio (Mestrado em Ensino do 1. e 2. ${ }^{\circ}$ Ciclo do Ensino Básico) Universidade do Minho, Braga, 2017. Disponivel em: http://hdlhandle.net/1822/57246. Acesso em: 5 ago. 2019.

GAGO, M. Ser Professor de História em tempos dificeis: início de um processo formativo, Antíteses, v. 11, n. 22, p. 507-519, 2018a. D0l: https://doi.org/10.5433/1984-3356.2018v11n22p507.

GAGO, M. Ser professor de História na paleta de cores de um profissionalismo complexo. Revista lbero-Americna de Educação Histórica, v. 1. n. 1, p. 107-125, 2018n. Disponível em: https://revistas.unila. edu.br/riaeh/index. Acesso em: 7 jun. 2019.

HOODLESS, P. Time and timelines in the primary school. London: Historical Association, 1996.

LEE, P. Progressão da compreensão dos alunos em História. In: BARCA, I. (org.). Perspectivas em Educação Histórica. Braga: CEEP, Universidade do Minho, 2001. p. 13-27.

LLONCH, N.; SOLÉ, G. Comparativa de metodologías y experiencias de educación patrimonial en la formación de futuros educadores de las Universidades do Minho (Portugal) y de Lleida (España). In: FONTAL, 0;; IBÁNEZ, A.; MARTíN, L. (coord.). Reflexionar desde las experiencias. Una visión completentaria entre España, Francia e Brasil. In: CONGRESO INTERNACIONAL DE EDUCACIÓN PATRIMONIAL, 2., 2014, Madrid. Actas [...] Madrid: IPCE/OEPE, 2014.

MACHADO, A. 0 potencial didático das narrativas (lendas, mitos e literatura infantil mito-simbólica) para o desenvolvimento do conhecimento histórico e da compreensão histórica nos alunos do $1^{\circ}$ e do $2^{\circ}$ ano. 2014. Relatório de Estágio (Mestrado em Ensino do 1. e 2. ${ }^{\circ}$ Ciclo do Ensino Básico) - Universidade do Minho, Braga, 2014. Disponível em: http://hdl.handle.net/1822/30139. Acesso em: 4 jun. 2019.

MELO, M. C. A formação de professores de História em Portugal: práticas pedagógicas e investigativas. Revista História Hoje, v. 4, n. 7, p. 41-61, 2015.

MOREIRA, F. 0 conceito de mudança em História: conceções de alunos do $1 .^{\circ}$ e $2 .^{\circ}$ CEB a partir da exploração de fontes visuais e objetuais. 2017. Relatório de Estágio (Mestrado em Ensino do 1. ${ }^{\circ} \mathrm{e}$ 2. Ciclo do Ensino Básico) - Universidade do Minho, Braga, 2017. Disponível em: http://hdl.handle. net/1822/57251. Acesso em: 5 ago. 2019.

NUNES, G. Azulejaria portuguesa e a valorização do património: interpretação de fontes patrimoniais iconográficas por alunos do $1^{\circ}$ e $2^{\circ}$ ciclo do ensino básico. 2015. Relatório de Estágio (Mestrado em Ensino do 1. ${ }^{\circ}$ e.$^{\circ}$ Ciclo do Ensino Básico) - Universidade do Minho, Braga, 2015. Disponível em: http:// hdl.handle.net/1822/41280. Acesso em: 5 ago. 2019.

OLIVEIRA, A. J. A compreensão do tempo e o desenvolvimento da competência da temporalidade em História em articulação com a Matemática em alunos do 4..$^{\circ}$ ano. 2016. Relatório de Estágio (Mestrado em Educação Pré-escolar e Ensino do 1. ${ }^{\circ}$ ciclo do Ensino Básico) - Universidade do Minho, Braga, 2016. Disponível em: http://hdl.handle.net/1822/43272. Acesso em: 10 jul. 2019. 
PIMENTEL, J. 0 desenvolvimento da compreensão histórica através de uma abordagem de aprendizagem cooperativa: um projeto com alunos do $3^{\circ}$ ano do Ensino Básico. 2013. Relatório de Estágio (Mestrado em Educação Pré-escolar e Ensino do 1. ${ }^{\circ}$ CEB) - Universidade do Minho, Braga, 2013. Disponivel em: http://hdl.handle.net/1822/28741. Acesso em: 5 ago. 2019.

PINTO, H. Educação histórica e patrimonial: conceções de alunos e professores sobre o passado em espaços do presente. 2011. Tese (Doutorado em Ciências da Educação, Especialidade de Educação em História e Ciências Sociais) - Instituto de Educação, Universidade do Minho, Braga, 2011.

PINHEIRO, J. Visita de estudo virtual versus visita de estudo in loco: contributos para aprendizagem de História no $1^{\circ}$ e $2^{\circ}$ Ciclo do Ensino Básico. 2017. Relatório (Mestrado em Ensino do 1. e 2..$^{\circ}$ Ciclo do Ensino Básico) - Universidade do Minho, Braga, 2017. Disponível em: http://hdll.handle.net/1822/59073. Acesso em: 5 ago. 2019.

PORTUGAL. Decreto-Lei n. 43, de 22 de fevereiro de 2007. Aprova o regime jurídico da habilitação profissional para a docência na educação pré-escolar e nos ensinos básico e secundário. Diário da República Eletrônico, 22 fev. 2007.

PORTUGAL. Decreto-Lei n. 65, de 31 de março de 2006. Aprova o regime jurídico dos graus e diplomas do ensino superior determina que a entrada em funcionamento de novas licenciaturas, mestrados ou doutoramentos está sujeita ao regime em vigor à data da sua publicação até à criação e funcionamento da agência de acreditação. Diário da República Eletrônico, 31 mar. 2006a.

PORTUGAL. Decreto-Lei n. 74, de 24 de março de 2006. Aprova o regime jurídico dos graus e diplomas do ensino superior, em desenvolvimento do disposto nos artigos $13 .^{\circ}$ a $15 .^{\circ}$ da Lei $n .^{\circ} 46 / 86$, de 14 de Outubro (Lei de Bases do Sistema Educativo), bem como o disposto no n. 4 do artigo $16 .^{\circ}$ da Lei n. $37 / 2003$, de 22 de Agosto (estabelece as bases do financiamento do ensino superior). Diário da República Eletrônico, 24 mar. 2006b.

RAMOS, F. C. 0 potencial didático da genealogia para a construção da identidade e desenvolvimento da compreensão histórica dos alunos do $1^{\circ}$ e $2^{\circ}$ Ciclo do Ensino Básico. 2016. Relatório de Estágio (Mestrado em Ensino do 1. e 2. ${ }^{\circ}$ ciclo do Ensino Básico) -Universidade do Minho, Braga, 2016. Disponível em: http://hdl.handle.net/1822/45201. Acesso em: 5 jun. 2019.

REIS, D. A literatura de ficção histórica na construção do conhecimento histórico. 2013. Relatório de Estágio (Mestrado em Ensino do 1. ${ }^{\circ}$ 2. ${ }^{\circ}$ Ciclo do Ensino Básico) - Universidade do Minho, Braga, 2013. Disponivel em: http://hdl.handle.net/1822/28997. Acesso em: 8 maio 19.

RÜSEN, J. Algumas ideias sobre a interseção da meta-história e da didática da história. Revista História Hoje, v. 5, n. 9, p. 159-170, 2016.

SOLÉ, G. A História no $1^{\circ}$ Ciclo do ensino básico: a concepção do tempo e a compreensão histórica das crianças e os contextos para o seu desenvolvimento. 2009. Tese (Doutorado) - Universidade do Minho, Braga, 2009. 
SOLÉ, G. Formação de professores e educadores em Educação Patrimonial na Universidade do Minho: estratégias pedagógicas em Educação Patrimonial. In: SOLÉ, G. (org.). Educação Patrimonial: novos desafios pedagógicos. Braga: Cied, Universidade do Minho, 2014a. E-book. Disponivel em: http://hdl. handle.net/1822/31352. Acesso em: 5 ago. 2019.

SOLÉ, G. 0 ensino de História a crianças: perspectivas de formação e investigação em Educação Histórica na Universidade do Minho (Portugal). In: SCHMIDT, M. A.; FRONZA, M. (org.). Consciência Histórica e Interculturalidade- Investigações em Educação Histórica. Curitiba: W.A. Editores, 2016. p. 169-184.

SOLÉ, G. 0 manual escolar no ensino primário em Portugal: perspectiva histórica e análise do ensino da História através deste recurso didático. Ensayos, Revista de la Facultad de Educación de Albacete, v. 29, n. 1, p. 43-64, 2014b. Disponível em: http://www.revista.uclm.es/index.php/ensayos. Acesso em: 5 ago. 2019.

SOLÉ, G. (org.). Educação Patrimonial: contributos para a construção de uma consciência histórica. Braga: Centro de Investigação em Educação, Instituto de Educação, Universidade do Minho, 2015. E-Book. Disponível em: http://hdl.handle.net/1822/40238. Acesso em: 5 ago. 2019.

SOLÉ, G.; VARELA, P. Modelo de formação de educadores/professores na área de didática de estudo do meio: análise de uma experiência de formação centrada no ensino da história a crianças. In: CONGRESSO INTERNACIONAL GALEGO-PORTUGUÊS DE PSICOPEDAGOGIA, 12., 2013, Braga. Anais [...] Braga: Centro de Investigação em Educação, Universidade do Minho, 2013. p. 2893-2911.

SCHMDT, M. A. Interculturalidade, humanismo e educação. histórica: formação da consciência histórica é mais do que literacia histórica? In: SCHMDT, M. A.; FRONZA, M. (org.). Consciência histórica e interculturalidade- investigações em educação histórica. Curitiba: W.A. Editores, 2016. p. 21-33.

UNIVERSIDADE DO MINHO. Instituto de Educação Regulamento do Estágio dos Mestrados em Ensino. Braga: Universidade do Minho, 2019.

VIEIRA, F. et al. No caleidoscópio da supervisão: imagens da formação e da pedagogia. 2. ed. Mangualde: Ed. Pedago, 2010.

VIEIRA, F. et al. 0 papel da investigação na prática pedagógica dos mestrados em ensino. In: CONGRESSO INTERNACIONAL GALEGO-PORTUGUÊS DE PSICOPEDAGOGIA, 12., 2013, Braga. Anais [...] Braga: CIEd, Universidade do Minho, 2013. p. 2641-1655.

Endereço para correspondência: Campus de Gualtar, 4710-057 Braga, Portugal; gsole@ie.uminho.pt

Roteiro, Joaçaba, U. 45, p. 1-26, jan./dez. 2020 | e21997 |E-ISSN 2177-6059 